\title{
Zr-Based Metallic Glass Coating for Corrosion Resistance Improvement of 45 Steel
}

\author{
Yunzhuo Lu*, Hongge Li, Hao Zhang, Guokun Huang, Huidong Xu, Zuoxiang Qin and Xing Lu \\ School of Materials Science and Engineering, Dalian Jiaotong University, Dalian 116028, People’s Republic of China
}

\begin{abstract}
Due to its good comprehensive mechanical properties and low cost, 45 steel has long been widely used for the manufacture of various components. However, the relatively low corrosion resistance of 45 steel has negative effect on its application and should be further improved. In this work, a $\mathrm{Zr}_{50} \mathrm{Ti}_{5} \mathrm{Cu}_{27} \mathrm{Ni}_{10} \mathrm{Al}_{8}$ metallic glass (MG) coating was successfully obtained on 45 steel by laser cladding method. The microstructure and the morphology of the MG coating were also examined. Corrosion test indicated that the glass coated 45 steel exhibited much higher corrosion resistance than that of bare 45 steel. This is due to the alloying element $\mathrm{Zr}$ and the structurally and chemically homogeneous structure of MG coating. [doi:10.2320/matertrans.M2017118]
\end{abstract}

(Received April 6, 2017; Accepted June 14, 2017; Published August 25, 2017)

Keywords: metallic glass coating, corrosion, 45 steel

\section{Introduction}

Metallic glasses (MGs), which are newcomers to the field of amorphous materials, have attracted great interests due to their remarkable mechanical, physical, and chemical proper$\operatorname{ties}^{1-3)}$. Their disordered atomic structures inherited from molten melts generate ultrahigh strengths, high elastic limits, low Young's moduli, good wear resistances, and excellent corrosion resistances, leading to comprehensive application potentials as structural and functional materials ${ }^{4-6)}$. However, the poor plasticity at room temperature and small dimensions in the region of only tens of millimeters severely limit the application scope of MGs ${ }^{7,8)}$. To break through the application restriction, exploiting attainable MGs as two-dimensional coatings is the most preferred way, since manufacturing coatings would not be limited by the thickness ${ }^{9,10)}$. Moreover, the MGs of excellent corrosion resistance, high hardness, and good abradability are good candidate for wear/corrosion resistant coating on metallic components ${ }^{11-13)}$.

Due to its good comprehensive mechanical properties and low cost, 45 steel has long been widely used for the manufacture of various components such as shafts, sleeves and gears. However, the relatively low corrosion resistance of 45 steel has negative effect on its application and should be further improved ${ }^{14)}$. Recently, several attempts have been made to fabricate the above mentioned MG coatings on steels to enhance their surface performances. For example, Basu et al. developed an Fe-based MG coating on AISI 4140 steel and found that the hardness and wear resistance of the coated layer was significantly improved as compared to the steel substrate $^{15)}$. Huang et al. deposited Fe-based MG coating onto 921A navy steel and found that the Fe-based coating exhibited better corrosion resistance than 921A navy steel ${ }^{13)}$. Ningshen et al. deposited Zr-based MG coating on type 304L stainless steel and achieved improved corrosion resistance in nitric acid medium ${ }^{16)}$. Wang et al. deposited amorphous Ni-based alloy on some carbon steels and obtained excellent corrosion resistances ${ }^{17)}$. Jayaraj et al. developed amorphous Ni-based layers on steel substrates and reported good corrosion behavior in $\mathrm{H}_{2} \mathrm{SO}_{4}$ solution ${ }^{18)}$. Raju et al.

*Corresponding author, E-mail: yunzhuohit@gmail.com coated amorphous Zr-based MG on carbon steel and observed significant increase in corrosion resistance in sulfate electrolytes compared to the base carbon steel ${ }^{19)}$.

Inspired by these results, the corrosion resistance of 45 steel can also be improved by the MG coating. Since $\mathrm{Zr}$ based MG exhibits excellent corrosion resistance, Zr-based MG coating can dramatically enhance the surface corrosion resistance of the 45 steel without destroying its performance in the substrate. Hence, the present work attempts to coat a Zr-based MG on 45 steel by laser cladding method. The corrosion behavior of the $\mathrm{Zr}$-based MG coating is assessed by comparing with that of the 45 steel substrate. The microstructure and the morphology of the cross-section of the $\mathrm{Zr}$ based MG coating were also examined.

\section{Experimental}

Laser cladding of Zr-based MG coating was performed with coaxial powder feeding laser solid forming system equipped with a $6000 \mathrm{~W}$ fiber laser. The diameter of laser beam was $2 \mathrm{~mm}$. The laser power was $1500 \mathrm{~W}$, and the travel speed of the laser beam relative to the substrate surface was $500 \mathrm{~mm} / \mathrm{min}$. Laser solid forming experiment were conducted inside a working chamber, which is filled with argon to keep the oxygen level lower than $10 \mathrm{ppm}$. Argon atomized $\mathrm{Zr}_{50} \mathrm{Ti}_{5} \mathrm{Cu}_{27} \mathrm{Ni}_{10} \mathrm{Al}_{8}$ powder in a size range of 20 $50 \mu \mathrm{m}$ was used for laser additive manufacturing process. The powder stored in the powder hoppers was fed through four coaxial nozzles by argon flow and injected into the melt pool created by the laser beam. The powder was delivered into the laser molten pool with the rate fixed at $20 \mathrm{~g} / \mathrm{min}$. In order to obtain continuous deposited layers, parallel tracks were partially overlapped, with an overlap fraction of $30 \%$. The 45 steel plates with the dimensions of $50 \mathrm{~mm} \times$ $50 \mathrm{~mm} \times 7 \mathrm{~mm}$ were used to act as substrates during laser additive manufacturing process. The substrate surfaces were ground with 600 grit $\mathrm{SiC}$ papers and thoroughly cleaned in ethanol prior to laser processing. In order to keep the substrate in a low temperature, the 45 steel plates were glued on a water-cooled copper plate with thermal conductivity silica gel. The microstructure characterization was examined using a Zeiss Supra 55 VP field emission scanning electron microscopy (SEM) equipped with energy dispersive X-ray 
spectroscopy (EDS) working at $15 \mathrm{kV}$ with a maximum resolution of $1 \mathrm{~nm}$. The phase analysis of the gas-atomized powders and as-sprayed Zr-based alloy coatings were performed using an X-ray diffractometer (XRD, EMPYREAN, PAN analytical) equipped with a $3 \mathrm{D}$ pixel semiconductor detector using $\mathrm{Cu}-\mathrm{Ka}$ radiation $(\lambda=0.154184 \mathrm{~nm})$. To evaluate the corrosion resistance, anodic polarization experiments were carried out in 3.5 mass $\% \mathrm{NaCl}$ aqueous solution at room temperature. A standard three-electrode electrochemical cell was designed to take electrochemical measurements. Prior to testing, the samples were exposed to the electrolyte for approximately $5 \mathrm{~min}$ to attain a steady-state open circuit potential. A saturated calomel electrode (SCE) and a platinum electrode worked as the reference electrode and the counter electrode, respectively. The specimen worked as working electrode with exposed area of $1 \mathrm{~cm}^{2}$ to the $\mathrm{NaCl}$ solution. During the potentiodynamic polarisation tests, the sweep rate was $1 \mathrm{mV} \mathrm{s}^{-1}$.

\section{Results and Discussion}

Figure 1(a) shows the SEM image of the Zr-based MG powder. Owing to the rapid solidification conditions, the majority of the particles produced by gas atomization in an argon atmosphere are spherical or near-spherical in shape. Some large powders have small satellites with a size of $5-10 \mu \mathrm{m}$. Figure 1(b) shows the XRD profile of the gas atomized $\mathrm{Zr}$-based MG powder using $\mathrm{Cu}-\mathrm{K} \alpha$ radiation. The presence of broad halo with diffused intensity in the XRD profile confirms that the powders obtained have a virtually completely amorphous phase, indicating that the present alloy composition is suitable for developing amorphous coating on steel substrate by laser cladding method with high cooling rate.

Figure 2(a) shows a typical macroscopic appearance of the Zr-based MG coating deposited on the 45 steel substrate. The microscopic secondary-electron image of the cross section perpendicular to the laser travel direction is shown in Fig. 2(b). Two different materials can be easily distinguished, namely the Zr-based MG on the upper side and the 45 steel on the lower side of the interface. The coating obtained is generally very dense, smooth, and without cracks. However, some pores are visible in the MG coating. There were no gaps, spallation or defects at the interface, revealing a strong adhesion between the metallic glass coating and the steel substrate. Such strong bonding between the two materials can be confirmed by the EDS profiles determined across the interface. As shown in Fig. 2(c), gradual concentration gradients across the interface are observed for all constituent elements, indicating that interdiffusion between the Zr-based MG coating and 45 steel takes place during the laser cladding process. The width of the interdiffusion zone is found to be about $23 \mu \mathrm{m}$, which demonstrates a good metallurgical bonding between the two materials.

The phased evolution form Zr-based MG (curve (i)) to 45 steel (curve (vi)) through the interface is analyzed by the XRD showing in Fig. 2(d). The XRD patterns are measured at the layers located at different depths within the sample.
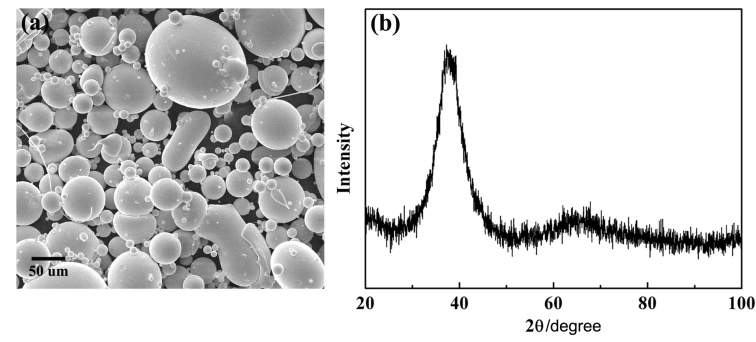

Fig. 1 (a) SEM image of the Zr-based MG powder, (b) XRD profile of the gas atomized Zr-based MG powder.
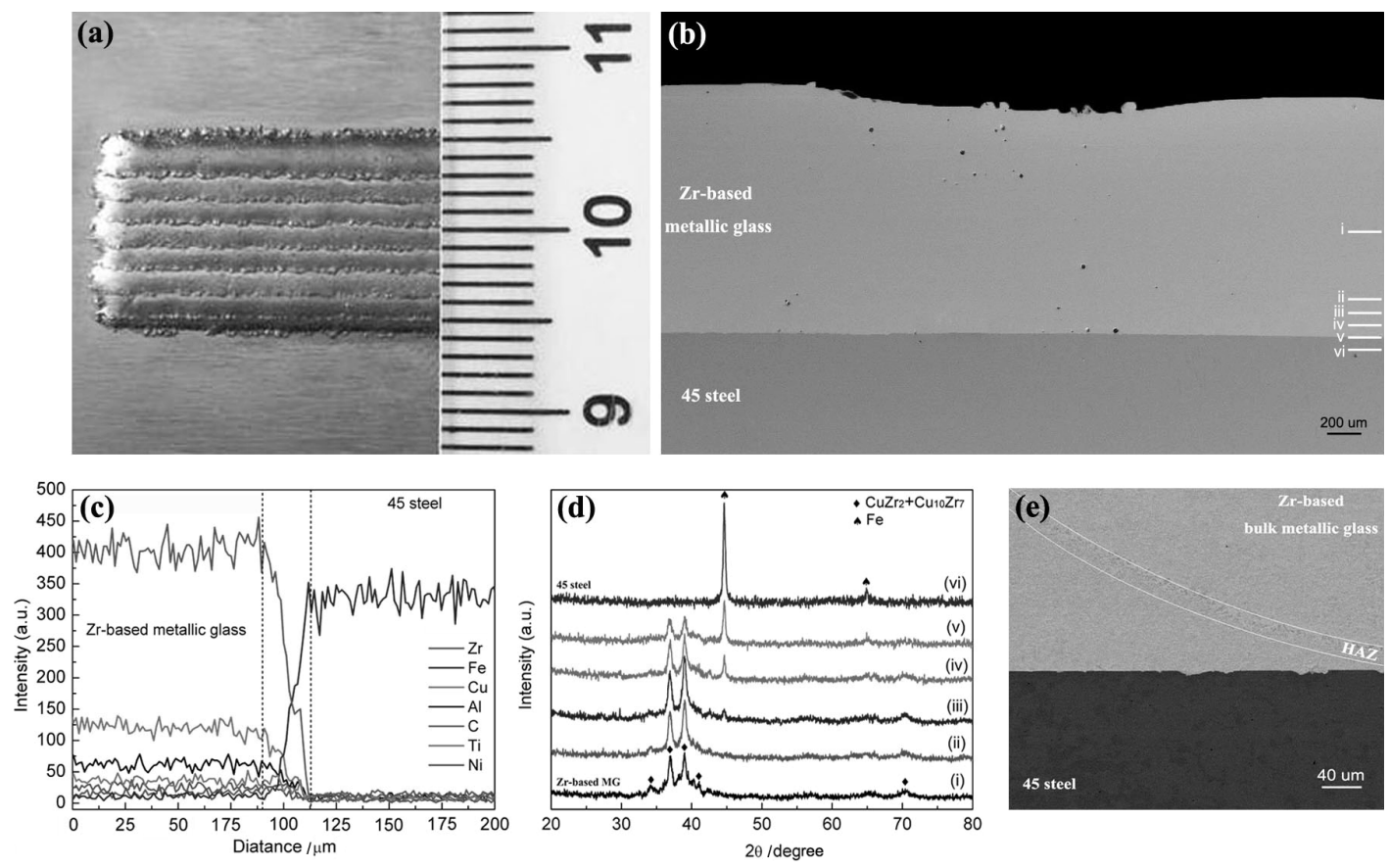

Fig. 2 (a) A typical macroscopic appearance of the Zr-based MG coating on 45 steel substrate, (b) Microscopic secondary-electron image of the cross section perpendicular to the laser travel direction, (c) EDS profiles determined across the interface between the metallic glass coating and the steel substrate, (d) XRD profiles of the Zr-based MG coating, (e) A typical magnified back-scattering morphology around HAZ region. 
The locations of these 6 layers are signed by white lines in Fig. 2 (b). As shown in curve (i), there is a broaden peak in 2 theta region of $33 \sim 42^{\circ}$, but there are still a few weak sharp crystal peaks in the XRD patterns, indicating the existence of a mixture of the amorphous and some crystalline phases in the deposited Zr-based MG coating. Many previous results have found that the crystallization is hard to be avoided in the laser deposited metallic glasses, since the heating rates in the heat-affected zone (HAZ) is lower than the critical heating rate required to avoid crystallization ${ }^{20,21)}$. Thus, in the present study, the deposited Zr-based MG coating is not fully amorphous. This can be confirmed by the typical magnified back-scattering morphology around HAZ region presented in Fig. 2(e). Numerous crystals embedded in the matrix can be observed in the HAZ region surrounded by white lines. As the location moves to the interface, a new phase appears and is characterized by crystalline Bragg peaks which match exactly with that of Fe. The intensities of the sharp crystalline peaks of Fe enhance gradually with the location accessing to the side of 45 steel. However, the intensity evolutions of the amorphous and crystalline phases detected in the Zr-based MG side are completely the reverse.

Figure 3 shows the anodic polarization curve for the $\mathrm{Zr}$ based MG coated 45 steel in $3.5 \mathrm{NaCl}$ solution, and the curve for bare 45 steel is also presented for comparison. The glass coated 45 steel shows a spontaneous passive behavior, indicating that a more protective passive film formed. Meanwhile, the glass coated 45 steel exhibits much lower corrosion current density and higher corrosion potential than that of bare 45 steel, proving that the Zr-based MG coating can effectively enhance the corrosion resistance of 45 steel, which is of great significance for the application of 45 steel in strongly corrosive environments. The excellent corrosion resistance of Zr-based MG coating derived from the homogeneous structure and alloying elements. The Zr-based MG exhibits the structurally and chemically homogeneous single phase nature and lack of crystalline defects including grain boundary. It provides the formation of a uniform passive film and hence also contributes to their high corrosion resistance ${ }^{22)}$. On the other hand, the Zr-based MG coating contains $\mathrm{Zr}$ element, which is an effective alloying element to provide a high passivation ability for the Zr-based MGs. As found in some previous works ${ }^{23,24)}$, the high corrosion resistance of Zr-based MGs was attributed to the formation of homogeneous and stable passive film enriched with $\mathrm{Zr}$ ele-

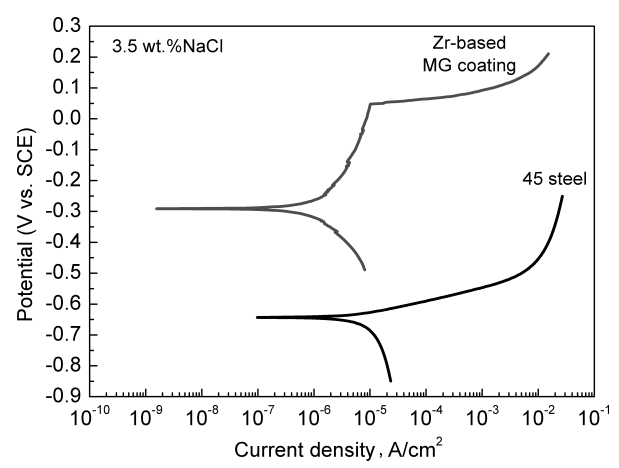

Fig. 3 Anodic polarization curve for the Zr-based MG coated 45 steel in $3.5 \mathrm{NaCl}$ solution, the curve for bare 45 steel is also presented for comparison. ment.

\section{Conclusions}

In the present work, a $\mathrm{Zr}_{50} \mathrm{Ti}_{5} \mathrm{Cu}_{27} \mathrm{Ni}_{10} \mathrm{Al}_{8} \mathrm{MG}$ coating was successfully obtained on 45 steel by laser cladding method. The Zr-based MG coating exhibited a mixture of amorphous and crystalline phases. The $\mathrm{Zr}$-based MG coating bonded strongly to the 45 steel substrate. The glass coated 45 steel exhibits higher corrosion resistance in $\mathrm{NaCl}$ solution than that of the bare 45 steel. The excellent corrosion resistance of Zr-based MG coating can be attributed to the alloying element $\mathrm{Zr}$ and the homogeneous structure.

\section{Acknowledgements}

This work was supported by the National Natural Science Foundation of China (NSFC) under Grant Nos. 51401041 and 51671042, China Postdoctoral Science Foundation under Grant No. 2015M570242, and Basic Research Project of Key Laboratory of Education Department of Liaoning Province under Grant No. LZ2015011.

\section{REFERENCES}

1) W.H. Wang, C. Dong and C.H. Shek: Mater. Sci. Eng. Rep. 44 (2004) 45-89.

2) A.L. Greer and E. Ma: MRS Bull. 32 (2007) 611-619.

3) K. Zhou, S. Pang, C. Chen, Y. Liu, W. Yang and T. Zhang: Mater. Trans. 58 (2017) 520-523.

4) B.A. Sun and W.H. Wang: Prog. Mater. Sci. 74 (2015) 211-307.

5) C.C. Dun, H.H. Liu, L. Hou, L. Xue, L.T. Dou, W.M. Yang, Y.C. Zhao and B.L. Shen: J. Non-Cryst. Solids 386 (2014) 121-123.

6) Y. Huang, J.C. Khong, T. Connolley and J. Mi: Int. J. Plast. 60 (2014) 87-100.

7) Y. Lu, Y. Huang, J. Shen, X. Lu, Z. Qin and Z. Zhang: J. Non-Cryst. Solids 403 (2014) 62-66.

8) D. Guo, K.C. Chan and L. Xia: Mater. Trans. 57 (2016) 9-14.

9) Y. An, G. Hou, J. Chen, X. Zhao, G. Liu, H. Zhou and J. Chen: Vacuum 107 (2014) 132-140.

10) S. Yugeswaran and A. Kobayashi: Vacuum 110 (2014) 177-182.

11) P. Yu, K.C. Chan, L. Xia, H.B. Yu and H.Y. Bai: Mater. Trans. 50 (2009) 2451-2454.

12) T.M. Yue, Y.P. Su and H.O. Yang: Mater. Lett. 61 (2007) 209-212.

13) Y. Huang, Y. Guo, H. Fan and J. Shen: Mater. Lett. 89 (2012) 229232.

14) W. Cai, F. Meng, X. Gao and J. Hu: Appl. Surf. Sci. 261 (2012) 411414.

15) A. Basu, A.N. Samant, S.P. Harimkar, J.D. Majumdar, I. Manna and N.B. Dahotre: Surf. Coat. Tech. 202 (2008) 2623-2631.

16) S. Ningshen, U.K. Mudali, R. Krishnan and B. Raj: Surf. Coat. Tech. 205 (2011) 3961-3966.

17) A.P. Wang, T. Zhang and J.Q. Wang: Philos. Mag. Lett. 86 (2006) 5.

18) J. Jayaraj, D.J. Sordelet, D.H. Kim, Y.C. Kim and E. Fleury: Corros. Sci. 48 (2006) 950

19) F. Schneider, W. Schwarz, J. Eckert, A. Gebert and V.R. Raju: Mater Corros. 53 (2002) 85.

20) G. Yang, X. Lin, F. Liu, Q. Hu, L. Ma, J. Li and W. Huang: Intermetallics 22 (2012) 110-115.

21) S. Pauly, L. Löber, R. Petters, M. Stoica, S. Scudino, U. Kühn and J. Eckert: Mater. Today 16 (2013) 37-41.

22) M. K. Miller and P. Liaw, Springer. Sci. Business. Media. (2007).

$23)$ A. Kawashima, K. Ohmura, Y. Yokoyama and A. Inoue: Corros. Sci. 53 (2011) 2778-2784.

24) N. Hua, L. Huang, J. Wang, Y. Cao, W. He, S. Pang and T. Zhang: J. Non-Cryst. Solids 358 (2012) 1599-1604. 